\title{
AC 2010-862: DEVELOPING THE AEROSPACE WORKFORCE: A BOEING EXPERIENCE
}

\section{Kenneth Van Treuren, Baylor University}

Dr. Van Treuren is a professor on the faculty in the Mechanical Engineering Department at Baylor University. He teaches the capstone Mechanical Engineering Laboratory course as well as courses in heat transfer, aerospace engineering, gas turbines, fluid mechanics, and wind power. His research interests include energy education and gas turbine heat transfer. He can be contacted at Kenneth_Van_Treuren@baylor.edu.

\section{Daniel Kirk, Florida Institute of Technology}

Dr. Daniel Kirk is an Associate Professor in the Mechanical and Aerospace Engineering Department at the Florida Institute of Technology. He teaches a variety of classes to include Aerodynamics and Flight Mechanics, Air-Breathing Propulsion, Rockets and Mission Analysis, and Aerospace Engineering Design. His research interests are in the areas of gas turbine and rocket propulsion systems.

\section{Tein-min Tan, Drexel University}

Dr. Tein-Min Tan is an associate professor of mechanical engineering and mechanics at Drexel University. He is a member of ASEE.

\section{Sridhar Santhanam, Villanova University}

Dr. Sridhar Santhanam is a Professor in the Mechanical Engineering department at Villanova University. He has taught a variety of classes in mechanics, design, manufacturing, and materials. His primary research interests are in the use of mechanics to model material behavior and manufacturing processes. 


\title{
DEVELOPING THE AEROSPACE WORKFORCE: A BOEING EXPERIENCE
}

\begin{abstract}
An engineer shortage is said to be looming on the horizon. There is considerable concern in the United States that not enough engineers are graduating from our colleges and universities to satisfy the demand. Boeing shares this concern and is seeking to become an important element in the development of emerging engineering talent. Boeing is well positioned to become a leader in developing the engineering pipeline to cultivate a world-class talent pool of engineering graduates, beginning in K-12 programs. This report first examines the "Desired Attributes of an Engineer" as defined by the National Academy of Engineering and Boeing. Quantitative data gathered from discussions with engineers show that perceptions of young engineers concerning their job skills, as outlined in the attributes, do not necessarily match the perceptions of their supervisors. Further study provides a snapshot of Boeing's involvement in the K-12 and university pipeline. The results of this study show that Boeing already actively participating in K-12 and university education. The conclusion from the literature shows that STEM education needs to be intentionally improved in the early school years and the paper suggests that Boeing and industry partners, because of their interest in the challenges of STEM education, could invest more of their resources to have a significant impact on STEM. Several recommendations are given to industry to position themselves for this challenge.
\end{abstract}

\section{Introduction}

The Boeing Company is a company dedicated to developing the best engineers in the world. Their commitment to the engineering education process is evident in the unique program called The Boeing Welliver Faculty Fellowship Program. This is a program that has been operated by Boeing every summer since 1995 . The Welliver program is a unique program designed to:

“... expose a small number of competitively selected professors from U.S. and international universities to key elements and the business realities of industry by enabling them to "look over the shoulder" of working professionals at several levels of the technical, business, and management career paths. They will leave the program with an understanding of Boeing's business including its research needs, with an improved understanding of the practical application of technical and business skills and with a network of contacts within Boeing and among their faculty peers that can form the basis of long-term relationships"

In all, 149 faculty from around the globe have participated in this program since its inception. The objectives of the Welliver Program are ${ }^{1}$ :

1. To provide faculty with a better understanding of the practical industry application of engineering, manufacturing, information technology and business skills

2. To help faculty enhance the content of undergraduate education in ways that will better prepare tomorrow's graduates for careers in a global environment 
3. To have faculty observe the Boeing environments, processes, and procedures with "fresh perspectives." Faculty will use their expertise to help identify areas for possible improvements and document their observations at Boeing.

The program is an obvious win/win situation for all involved. The authors were privileged to participate as Boeing Welliver Fellows this past summer of 2009. The fellows were worked at several locations of the Boeing Company which provided the opportunity to observe different aspects of Boeing's operation. The authors' primary locations were St. Louis, MO, Seattle, WA, Philadelphia, PA and Huntington Beach, CA. While at these locations, the authors had freedom to visit all aspects of Boeing site, from assembly lines to research and development laboratories. One requirement for the fellows was to write an individual report on their experiences. For Boeing, the individual report was a great opportunity to have a "fresh" set of eyes looking at how the organization operates. For the fellows, the experiences gained by each participant definitely enhance teaching at home institutions. The individual final report was written and presented to key personnel of the Boeing administration at the end of the summer program.

Another requirement of the program was to accomplish a group research project, from a list proposed by the Boeing leadership, on a specific topic of concern to Boeing. The topic chosen by the authors was to examine the state of the engineering education pipeline and offer advice to Boeing on how to become an integral element in the cultivation and development of emerging engineering talent. The group project was accomplished as a team, even though the team members were sited at different locations. This collaborative project was written as a final report and also presented to the leadership at the end of the summer program.

The approach chosen by the authors was to first identify the key characteristics of an engineer, next to examine the current state of the STEM education pipeline and Boeing's interaction with the STEM process, and finally, to present recommendations to Boeing based on a critical analysis. Thus, this paper will begin by studying the desired attributes of an engineer, particularly a Boeing engineer. Supporting information was gleaned from data gathered through research from the open literature and discussions with both early career engineers and supervisors at Boeing. From this snapshot of information, conclusions were drawn as to how well these young engineers met the desired attributes. Also examined was the K-12 and college STEM education pipeline and, in particular, Boeing's current role in this area. Based on observations gained through this study, recommendations were proposed for an educational effort in STEM education.

\section{Attributes of an Engineer: A Study}

A study, recently commissioned by the National Academy of Engineering (NAE), identified the desired attributes of the Engineer of $2020^{2}$. These traits are:

\section{- Possesses strong analytical skills}

- Exhibits practical ingenuity; possesses creativity

- Good communication skills with multiple stakeholders

- Business and management skills; Leadership abilities

- High ethical standards and a strong sense of professionalism

- Dynamic/agile/resilient/flexible 


\section{- Lifelong learners}

- Ability to frame problems, putting them in a sociotechnical and operational context

A similar study, conducted by Boeing, resulted in the Boeing list of 'Desired Attributes of an Engineer," as seen below in Figure 1.

\section{Boeing List of "Desired Attributes of an Engineer"}

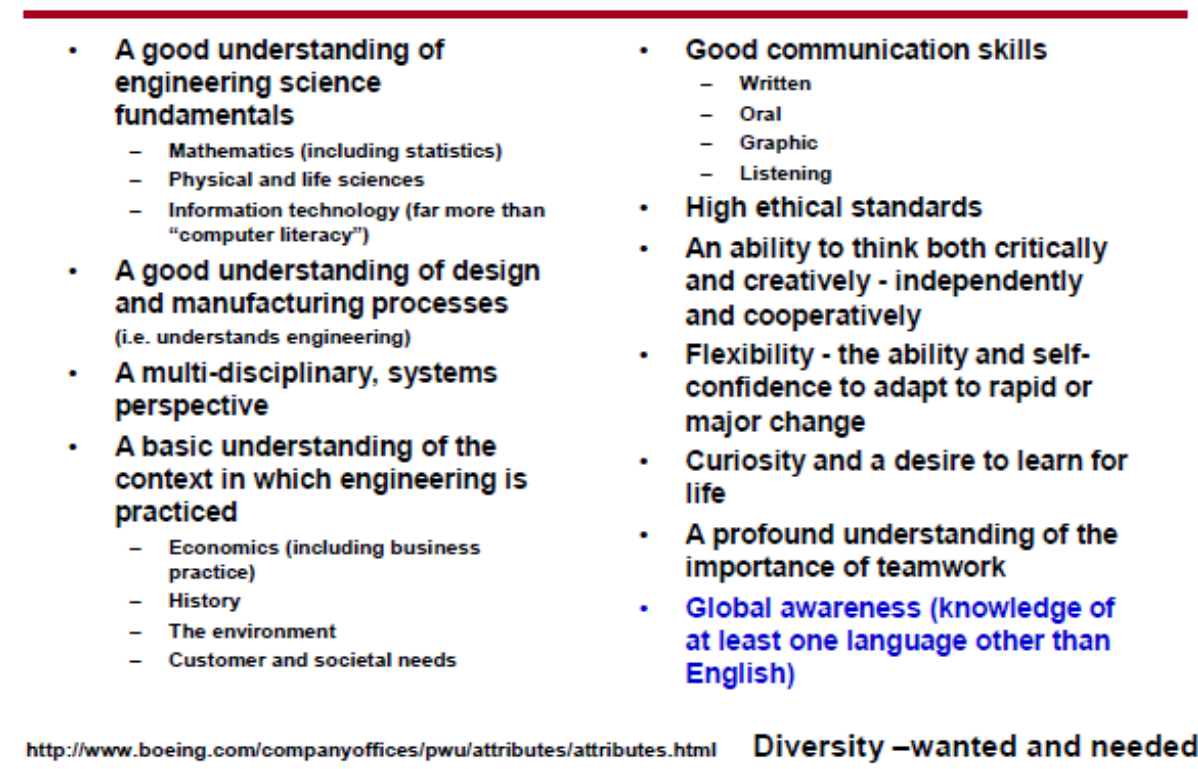

Figure 1 Desired Attributes of an Engineer ${ }^{3}$

Clearly, there is a lot of synergy between the NAE definition and the 'Boeing' Engineer. Strong analytical skills, communication skills, and life-long learning are some of the key common characteristics of both the NAE and Boeing Engineer. Boeing continues to uphold these attributes as desirable in new engineers.

The authors decided to take these attributes and observe how effective Boeing was with hiring engineers displaying these qualities. This would be accomplished using a series of questions to for discussion at each of the locations represented among the authors. These discussion and the ensuing results are clearly the observations of the faculty fellows and are flavored by the academic nature of the authors. The sample size is small. The results in no way are a definitive answer to the questions poised. Results gleaned from discussions with early career engineers and supervisors, as well as the experiences of the authors at their own institutions, are a beginning point for future discussion on this important topic.

\section{Structured Qualitative Discussion Topics and Talking Points}

Because of industry observations of the authors prior to becoming Welliver Fellows, an interest developed in seeking to explore the "ideal" traits of an engineer. This is especially of interest to academic programs that train engineers. A list of topic was developed. These discussion topics were part of conversations with supervisors and new engineers. With supervisors, the emphasis 
was on their perceptions of the new engineers and the level of quality of their skill sets. For new engineers, the focus was on their preparation for work. While the information gathered involved engineers on the site locations, the questions are just as valid at any industrial site. Again, since number of discussions was small compared to the number of employees at a particular sight, the results are just one segment of information and must be taken as such. Questions were developed for each group, both 1) supervisors, mentors, and managers and 2) new employees.

\section{Supervisors, Mentors and Managers:}

- How and when should Boeing develop a pool of potential candidates for engineering positions?

- How do you view U.S. domestic and international supply of engineering students (i.e. quality, skill sets, etc.)? Where should Boeing concentrate its efforts?

- What are your impressions of metrics that HR uses to identify a pool of potential applicants for new positions?

- What do you think of use of 'key words' when sifting through large applicant resume pools?

- Did you have input on these key word choices?

- What are metrics that you use when evaluating a candidate? Are there conflicts of coordination between HR and Engineering regarding appropriateness or ranking of potential new employees?

- How do you track progress of a new employee (level 1) during first few years of development?

- How do you reward/acknowledge good work and progress of your new employees or younger engineers?

- How aware are you of professional intentions that new employees have when joining the company? Do you encourage new employees to start thinking about technical vs. managerial career paths?

- Are you aware of 'Engineering Skills Rotation Program' and other training programs for new employees?

- What are strongest and weakest points of new employees you have worked with?

- Does Boeing need "very best and brightest" new employees?

- At what educational level is it appropriate for Boeing to become involved in educational process?

- Are you partnered with either an undergraduate/graduate university or a K-12 school? If so what are the strengths, weaknesses, opportunities and threats to these relationships. Are encouraged to participate and are you rewarded for this involvement?

- How open is organization to get involved with university partnerships or K-12 education in math and science?

\section{New Engineers and Interns:}

- Is your mentor/boss aware of your personal near and long term professional plans? If yes, how does he/she know them? If no, why do you think he/she does not know?

- Is your career progressing along path you envisioned?

- Are you career aspirations aligned with Boeing's strategic goals and vision? 
- How is success now measured differently at Boeing than when you were in college? Are you aware of how success is measured and how much does it mean to you?

- What could have been more effective during your K-12 years to prepare you for college?

- What could have been more effective during your college years to prepare you for Boeing?

- At what age and in what circumstances did you first learn about engineering?

- At what age and in what circumstances did you first learn about Boeing?

- What were your first impressions?

- When did you first want to work for Boeing or a company like Boeing?

- Do you want to retire with Boeing?

- What skills (technical, communications, and leadership) are proving to be the most valuable in your job at Boeing?

- What experiences in College have proven to be most beneficial for your career at Boeing?

- Where do you see yourself 5-10 years? How supportive is your manager in providing you opportunities?

- How receptive are your peers and superiors to your ideas?

- Are you partnered with either an undergraduate/graduate university or a K-12 school?

- If so what are the strengths, weaknesses, opportunities and threats to these relationships.

- Are encouraged to participate and are you rewarded for this involvement?

- How open is organization to get involved with university partnerships or K-12 education in math and science?

- What are top two or three skills that future Boeing engineers are going to need to succeed?

\section{Quantitative Interview Discussion Topics Used Throughout the Fellowship}

While the discussion topics and talking points were a useful means to gain a qualitative appreciation for how supervisors and managers perceived the quality of new employees, a more quantitative metric was pursued. To do so a series of 18 questions, which map directly to Boeing's 'Desired Attributes of an Engineer,' were explored. The scoring on each topic ranges from 1 to 5, with 1 being a poor score and 5 being excellent. The resultant information gathering exercise would be of interest across all industries that hire engineers. It is of particular interest to academics as they mature new engineers. The information would also be a valuable feedback device to both new engineers and industries alike. The questions used for this study can be found below.

\section{Interview Questions for New Engineers}

\begin{tabular}{|c|c|c|c|c|c|c|}
\hline \multirow{2}{*}{\multicolumn{2}{|c|}{ Did your undergraduate education prepare you in the following areas?: }} & \multicolumn{5}{|c|}{ Low to High Emphasis } \\
\hline & & 1 & 2 & 3 & 4 & 5 \\
\hline 1 & A good understanding of engineering science fundamentals & & & & & \\
\hline 2 & Mathematics (including statistics) & & & & & \\
\hline 3 & Physical and life sciences & & & & & \\
\hline 4 & Information technology (far more than "computer literacy") & & & & & \\
\hline 5 & A good understanding of design and manufacturing processes. & & & & & \\
\hline 6 & A multi-disciplinary, systems perspective. & & & & & \\
\hline 7 & A basic understanding of the context in which engineering is practiced. & & & & & \\
\hline 8 & Economics (including business practices) & & & & & \\
\hline 9 & History & & & & & \\
\hline 10 & The environment & & & & & \\
\hline 11 & Customer and societal needs & & & & & \\
\hline
\end{tabular}




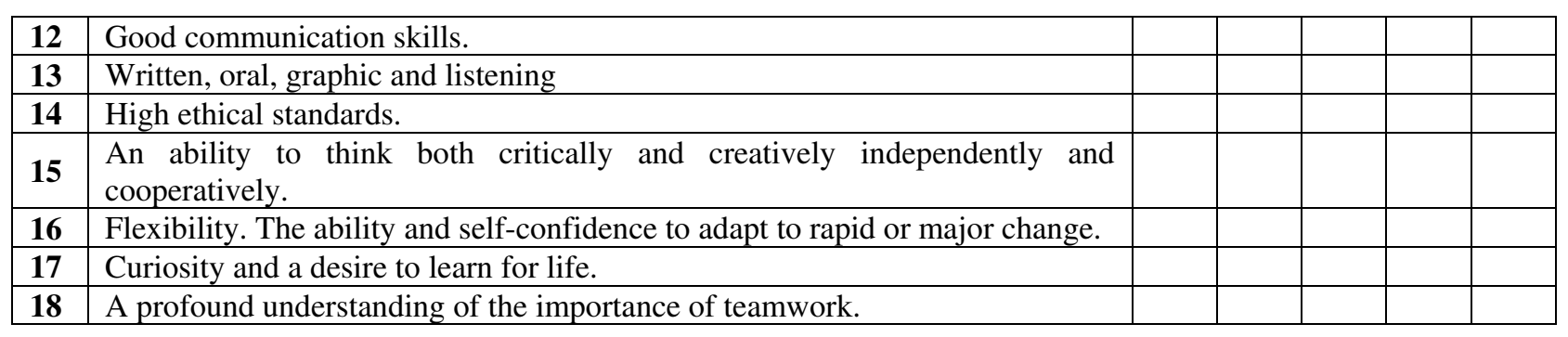

\section{Interview Questions for Supervisors}

\begin{tabular}{|c|c|c|c|c|c|c|}
\hline \multirow{2}{*}{\multicolumn{2}{|c|}{$\begin{array}{l}\text { How has employment at Boeing used these skills or encouraged you to develop } \\
\text { increased understanding in these areas?: }\end{array}$}} & \multicolumn{5}{|c|}{ Low to High Emphasis } \\
\hline & & 1 & 2 & 3 & 4 & 5 \\
\hline 1 & A good understanding of engineering science fundamentals & & & & & \\
\hline 2 & Mathematics (including statistics) & & & & & \\
\hline 3 & Physical and life sciences & & & & & \\
\hline 4 & Information technology (far more than "computer literacy") & & & & & \\
\hline 5 & A good understanding of design and manufacturing processes. & & & & & \\
\hline 6 & A multi-disciplinary, systems perspective. & & & & & \\
\hline 7 & A basic understanding of the context in which engineering is practiced. & & & & & \\
\hline 8 & Economics (including business practices) & & & & & \\
\hline 9 & History & & & & & \\
\hline 10 & The environment & & & & & \\
\hline 11 & Customer and societal needs & & & & & \\
\hline 12 & Good communication skills. & & & & & \\
\hline 13 & Written, oral, graphic and listening & & & & & \\
\hline 14 & High ethical standards. & & & & & \\
\hline 15 & $\begin{array}{l}\text { An ability to think both critically and creatively independently and } \\
\text { cooperatively. }\end{array}$ & & & & & \\
\hline 16 & Flexibility. The ability and self-confidence to adapt to rapid or major change. & & & & & \\
\hline 17 & Curiosity and a desire to learn for life. & & & & & \\
\hline 18 & A profound understanding of the importance of teamwork. & & & & & \\
\hline
\end{tabular}

\section{Data Analysis of Quantitative Interview Discussion Topics}

Data was obtained from 37 conversations/interviews; 16 new engineers (less than 5 years of experience) and 21 supervisors, mentors, or program managers. These results represent perceptions of those interviewed and do not necessarily reflect the position of the parent organization. Again, not a large sample size however, interesting observations can be made that mirror industry wide trends. There are two ways to examine the data:

1. Assessment of absolute scores. In this case scores given by new engineers and supervisors were close to each other, say within 1 point. If both scores were high, we have excellent agreement that the skill being measured is being utilized. If both scores were low, we have agreement that the skill being measured is not understood or being utilized.

2. Assessment of differences. In this case significant deviations exist between the score report by the new engineer and by the supervisor.

The bar graph shown in Figure 2 provides the data for each of the new engineer and supervisor answers to the 18 questions posed based on the 'Desired Characteristics of an Engineer'. The data suggests that in several key areas such as engineering fundamentals (Q1), information 
technology (Q4), ethics (Q14), creative thinking (Q15), and flexibility and adaptive thinking (Q16), both the new engineer and the supervisor are close in agreement that these skills have been adequately mastered and are being appropriately utilized. In other instances, lower scores in areas such as an appreciation of economics (Q8), history and historical context (Q9), and the environment (Q9), indicate both the new engineer and the supervisor agree that these skills are not adequately developed prior to becoming a practicing engineer. These lower scores are also areas of interest in the ABET assessment process and point to areas that need improvement in the academic process. This is important information for universities and colleges.

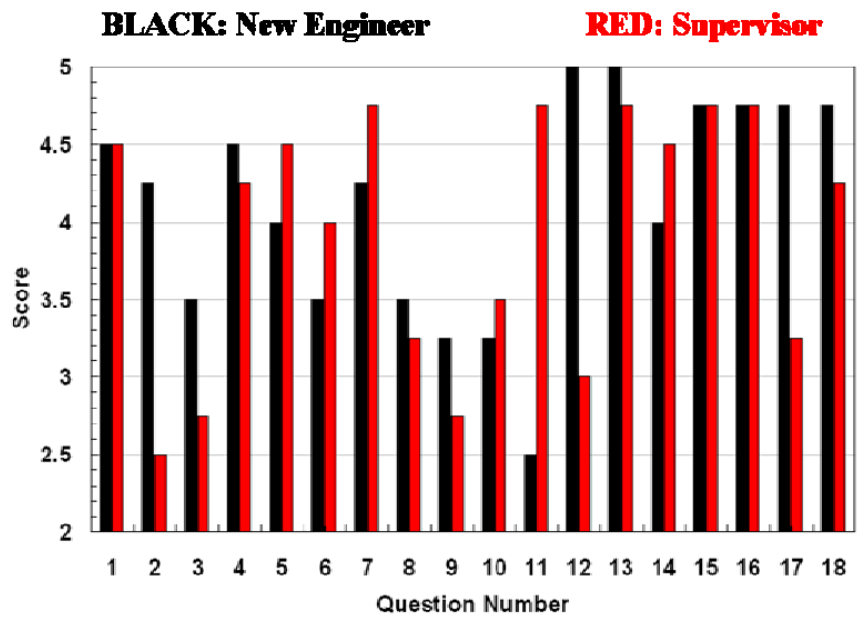

Figure 2 Results of interview data from 37 participants showing answers to 18 key questions associated with Boeing's 'Desired Attributes of an Engineer'

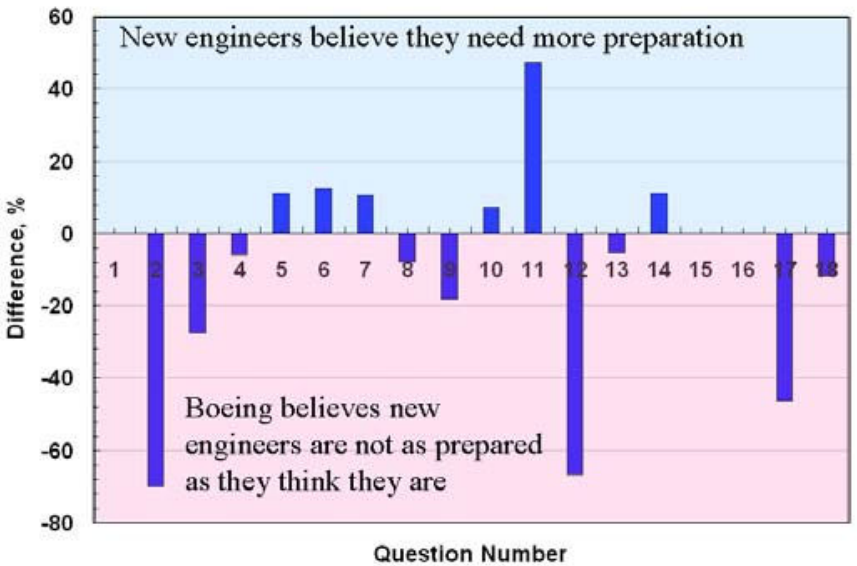

Figure 3 Results of the percentage difference between answers supplied by new engineers and supervisors, normalized by supervisor response score

Table 1 Figure 3 Summary

\begin{tabular}{|l|l|c|c|c|}
\hline \multicolumn{2}{|c|}{ Attribute } & $\begin{array}{c}\text { Supervisors (S) - } \\
\text { New Engineers Not } \\
\text { Prepared }\end{array}$ & $\begin{array}{c}\text { Both Agree - } \\
\text { Skills Adequate }\end{array}$ & $\begin{array}{c}\text { New Engineers (NE) } \\
\text { - Need More } \\
\text { Preparation }\end{array}$ \\
\hline $\mathbf{1}$ & Engineering science fundamentals & & X & \\
\hline $\mathbf{2}$ & Mathematics & X (NE disagree) & & \\
\hline $\mathbf{3}$ & Physical and life sciences & X (NE disagree) & & \\
\hline $\mathbf{4}$ & Information technology & X (Slight) & & X (Slight) \\
\hline $\mathbf{5}$ & Design and manufacturing processes & & & X (Slight) \\
\hline $\mathbf{6}$ & $\begin{array}{l}\text { A multi-disciplinary, systems } \\
\text { perspective }\end{array}$ & & & \\
\hline $\mathbf{7}$ & $\begin{array}{l}\text { Context in which engineering is } \\
\text { practiced }\end{array}$ & & & \\
\hline $\mathbf{8}$ & Economics & $\mathbf{X}$ (Slight) & $\mathbf{X}$ (Slight) \\
\hline $\mathbf{9}$ & History & $\mathbf{X}$ (Slight) & & \\
\hline $\mathbf{1 0}$ & The environment & & & \\
\hline $\mathbf{1 1}$ & Customer and societal needs & & & \\
\hline $\mathbf{1 2}$ & Good communication skills & $\mathbf{X}$ (NE disagree) & & \\
\hline $\mathbf{1 3}$ & Written, oral, graphic and listening & $\mathbf{X}$ (Slight) & & \\
\hline $\mathbf{1 4}$ & High ethical standards & & & \\
\hline $\mathbf{1 5}$ & $\begin{array}{l}\text { An ability to think both critically and } \\
\text { creatively, independently and }\end{array}$ & & & \\
\hline
\end{tabular}




\begin{tabular}{|c|l|c|c|c|}
\hline & cooperatively & & $\mathbf{X}$ & \\
\hline $\mathbf{1 6}$ & $\begin{array}{l}\text { Flexibility - the ability and self- } \\
\text { confidence to adapt to rapid or major } \\
\text { change }\end{array}$ & $\mathbf{X}$ (NE disagree) & & \\
\hline $\mathbf{1 7}$ & Curiosity and a desire to learn for life & $\mathbf{X}$ (Slight) & & \\
\hline $\mathbf{1 8}$ & Importance of teamwork & & \\
\hline
\end{tabular}

Useful information can also be gleaned by indentifying skill areas where there are large percentage differences between the answers given by the new employee and the manager. This difference comparison is shown in the data in Figure 3. If the bar appears above the zero-line it means that the new engineer believes that they need more education and training to competently deal with the issue, whereas the supervisor believes that the training and preparation for this skill is adequate. Again, the data suggests areas already known in the academic literature. The areas of largest deviation below the zero-line show that mathematics $(\mathrm{Q} 2)$, written communication $(\mathrm{Q}$ 12) and a willingness and awareness to engage in life-long learning ( $Q$ 17) are areas needing more emphasis in engineering programs. This again reflects what is being highlighted in ABET outcomes. Table 1 summarizes the main conclusions from the study. If "X (Slight)" appears in a column, this indicates the results for both New Engineers (NE) and Supervisors (S) are approaching agreement and, thus, would be close to appearing in the "Adequate" or center column.

What next?

Based on this study and after examining other studies in the open literature, it is clear that there is concern in industry and Boeing about the quality of STEM graduates entering the workforce. There is also deep concern about the dwindling numbers of STEM graduates emerging from the STEM pipeline. The STEM education pipeline is in disrepair and needs urgent action for renewal.

\section{The Current Landscape: K-12, University, and Early Boeing Engineers}

There are many players in K-12 STEM education with Boeing being one. Boeing is also deeply involved with Colleges and Universities.

BOEING and K-12 STEM

Education is one of the five focus areas of the Boeing Global Corporate Citizenship (GCC) component. In K-12 education, Boeing promotes the development of quality learning environments in the areas of math, science and literacy necessary for future success in the workforce and in life. The goals of Boeing's education investment are to

- Promote teacher professional development and improve school leadership

- Improve outcomes for the largest number of students possible, including targeted investments for underserved populations

- Encourage school systems to adopt standard, aligned curricula 
The Boeing GCC network consists of both full- and part-time professionals who invest corporate and local resources in their communities (i.e., via volunteerism and locally based intellectual capital) according to local strategies based on community need. Boeing believes that the strength of locally based GCC representatives is their detailed knowledge of their communities as well as the ability to place that knowledge into its global context.

The Employees Community Fund (ECF) is a unique employee-owned and directed givingprogram that allows employees to support the needs of their local communities via taxdeductible recurring payroll deductions or one-time gifts. Employee contributions are either directed to an ECF pooled fund or to an eligible nonprofit of the employee's choice. Boeing pays all administrative costs for the ECF so that $100 \%$ of every employee dollar contributed goes to support the community. Funding decisions for the pooled funds are the sole responsibility of local ECF boards in accordance with the best interests of the community and its membership. Board members perform their duties on an unpaid volunteer basis, usually requiring a good deal of personal time.

In 2008, Boeing corporate charitable cash contributions and in-kind donations totaled \$57.9 million. Employee and retiree contributions totaled more than $\$ 49$ million in 2008, which included more than $\$ 32$ million in payroll deductions through the ECF. Of the $\$ 57.9 \mathrm{M}$ total cash contributions, $\$ 27 \mathrm{M}$, or $47 \%$ was used in the education focus area.

An outstanding example of Boeing employee involvement in K-12 program is the Ridley Park, PA K-12 Process Management Team. The team was recognized by the Boeing Company in 2008 as a winner of the Change Agent Award for efforts to improve the future workplace by mentoring Philadelphia area schoolchildren of diverse backgrounds -- many of them from lowincome communities -- who have an interest in science, technology, engineering, math and technical careers. Team members have become Boeing ambassadors to hundreds of students, boys and girls, throughout the metropolitan area. The team has hosted school groups, conducted tours of Boeing's wind tunnel and held displays of student posters and science fair entries. They have arranged for employees to go into schools to talk about aerospace careers, mentor a radiocontrol airplane project, and judge a robotics competition and much more. Several new Boeing employees can point to specific events or interactions with members of this team as profound influences that led them to pursue an aerospace career and join the company. Other activities of the Ridley Park Process Management Team include

- Explorer Career Program (through Boy Scouts)

- Teachers in Space Camp

- Boeing ambassadors to local high schools

- Tours of Boeing facility

- Student posters and science fair

- Seminars about aerospace careers

- Mentor a radio-control airplane project

- Judge robotics competitions Girls in Science/Engineering Camp at U. of Penn.

- idTech camp at Villanova U. and Rider U.

- Materials and Process Camp at Drexel

- Widener High School student Engineering Camp 
- Delaware area STEM camps

- PA Airport Flying Field Summer Camp

- Government Opportunity for Apprentice Program

- Temple University Robotics 2009

Examples of locally based K-12 programs at other Boeing sites include

- Boeing Huntington Beach:

- Educator Enrichment Day

- Boeing Explore Engineering Summer Science Camp

- REACH program for inner city schools

- $\quad$ Boeing St. Louis

- Robotic Club: Mentors high school robot competition

- Educators to SPACE CAMP Program

- Boeing Huntsville

- Educators to SPACE CAMP Program

The strengths of these locally based K-12 programs can be summarized as follows:

- These programs have corporate interest and support

- Boeing engineers are experts in STEM, eager to share knowledge with the next generation

- Participants are associated with local school districts and understand the needs of the schools

- Programs have the ability to impact a large number of schools

- Boeing employees are role models for women and minorities

However, these locally based programs do have their weaknesses.

- Current resources constrain growth of

- New and different programs

- Replication of successful programs in other communities

- Not all employees are aware of the opportunities/possibilities

- Many K-12 schools are unaware of the opportunities/possibilities

- There is no recognition given to employees, within the career paths, for service to K-12 programs

Boeing is clearly interested and involved in the K-12 education initiatives however more could be done. In fact this is the same advice that could be given to any major industry which employs engineers. The Vice President of Operations for Project Lead The Way, Inc. recently stated that "Lockheed Martin sets the standard of commitment to education and to the nation with their innovative and comprehensive Engineers in the Classroom initiative."4 If Boeing or any other industry leader desires to have a significant impact on K-12 education, then they must ask the following questions:

- Do we really have a commitment to K-12 STEM education? Is it more than just words? 
- Are we really committed to investing time and money in K-12 STEM education, and then recognizing efforts of participants as valuable?

Boeing has several successful K-12 programs operating at various locations. This information should be shared across the Boeing organization, as well as with other industries, and the successful programs replicated when appropriate at other sites.

\section{BOEING: COLLEGES and UNIVERSITIES}

\section{Undergraduate Engineering: Supply Declining}

According to Daniel Sturtevant in "America Disrupted: Dynamics of the Technical Capability Crisis," the number of undergraduates earning engineering degrees in the United Sates declined $42 \%$ between 1985 and $2006^{5}$. This is somewhat disturbing as it shows the supply of engineers is shrinking even though engineers are well paid as a profession. This seems to run counter to economic theory which implies that a short supply usually means high demand and would attract many new students. Instead, there are fewer students entering engineering academic programs.

The dilemma facing undergraduate engineering is just a snapshot of the overall picture. Approximately four million students start school every year, however only 60,000 students finish with engineering degrees, or about $1.5 \%$ of the students who started (See Figure 3 below). Another statistic shows that $82 \%$ of students fall out of the pipeline prior to leaving junior high.

There are several reasons put forth by Sturtevant for this decline. The current educational system requires math mastery before the $9^{\text {th }}$ grade. If this is not achieved then it will be difficult to run what is known as "The STEM Gauntlet." From junior high to high school, math and science courses get more technically complex. This leads to "losing" additional students at each step along the way.

K-12 teacher quality in the United States is declining as are teaching salaries. Low pay means students will not be attracted to the teaching profession which will eventually lead to labor shortages. Teacher quality has been shown to be the primary determinant of student performance. Involved and enthusiastic teachers make a difference.

Another shortcoming of the system is the lack of STEM emphasis in elementary schools. STEM issues must be addressed earlier in the educational pipeline, as early as elementary school. 


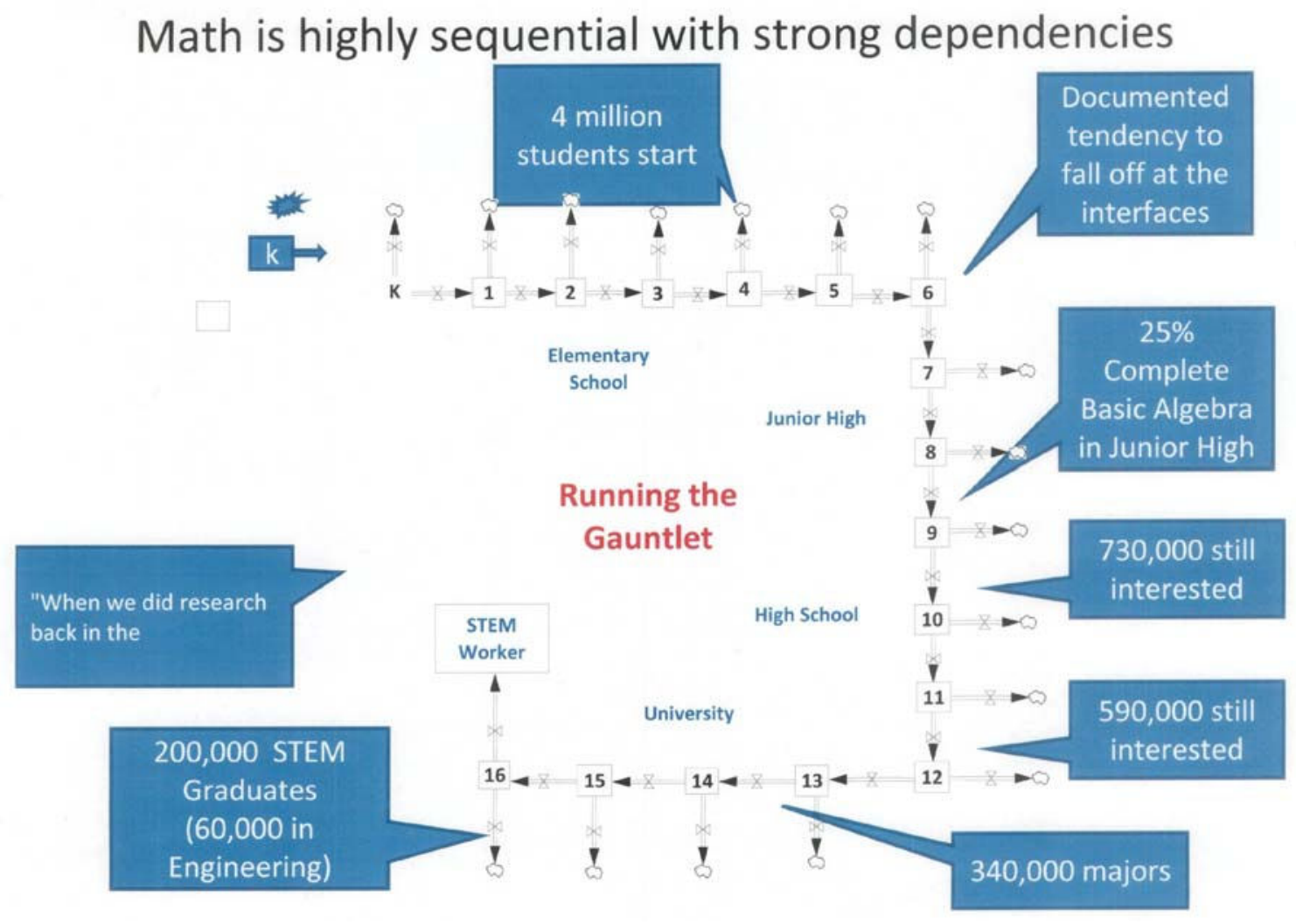

Figure3 : Running the Gauntlet ${ }^{5}$

Boeing's Current University Relations: Strengths and Weaknesses

Boeing has had a long and successful history of interaction with colleges and universities in the U.S. There have been several facets to this relationship. The company encourages employees to further their learning by supporting continuing education. Universities near Boeing facilities benefit by having a large pool of motivated students from Boeing for their undergraduate and graduate programs.

There is also a significant amount of collaboration that occurs between Boeing and leading research universities on technological problems of interest to Boeing. Boeing has also worked to improve undergraduate curricula by working with a few select universities. The Higher Education Integration Board has played a pivotal role in all these interactions.

There are a number of other significant initiatives that Boeing has undertaken to foster a strong relationship with universities. Boeing has identified a subset of approximately 150 targeted universities for strategic engagement. Each of these schools is assigned an Executive Focal, typically a Boeing executive with ties to the school, whose objective is to facilitate the interaction between Boeing and the designated university. 
The Welliver Faculty Fellowship program, which supported the authors, is a unique program that Boeing initiated in 1995 for university faculty to experience the working environment at Boeing. Each year Boeing also brings in a significant number of student interns and co-ops.

Clearly, Boeing interacts in diverse ways with colleges and universities. One can identify several strengths of this interaction.

- The Higher Education Board that coordinates all higher education related activities is very capable.

- Boeing engages with a large, broad base of target universities and colleges ( 150)

- The use of Executive Focals to be the primary means of engagement with universities is unique to Boeing.

- Approximately half of Boeing's charitable contributions are targeted to improve education in K-12, colleges, and universities.

- A great way to recruit future employees is to bring them in as co-ops and interns

- The Welliver Fellowship program

- The Learning Together Program

- Research partnerships with 8 universities in target areas of research

- Certificate programs

- Boeing Technical fellows at Universities

There are some weaknesses.

- Some Executive Focals are ineffective

- Universities have unreasonable expectations of Boeing

- Universities not well-informed about Boeing's intentions/desires/motivations

- Executive Focals not allocated enough time and money

- Boeing employees do not have clear ideas about Boeing's involvement with schools

- Vocational/Trade Schools do not get attention.

\section{NEW EMPLOYEES AT BOEING}

\section{The Hiring Process}

The hiring process is one that involves managers on all levels. According to Boeing first and second level managers, new employees are typically found through internships. This is the preferable method to hire new engineers as it gives the company an opportunity to observe the individual for several weeks prior to an offer of employment. It is not unheard of to receive 300500 applications for a single internship position. Schools with desired program experience are given some preference. Managers are looking for something unique that distinguishes the individual's resume, such as a personal experiences to include a pilot's license, leadership positions, or design, build, fly type projects. Often the interns can be B.S. students waiting for graduate school or graduate students themselves. Once the pool is narrowed down, a thirtyminute telephone interview is usually conducted with the finalists to determine the "fit." Interns who are hired in some organizations work on a group intern project. A final report/presentation is required. Exceptional interns are offered Engineering Leave of Absence (ELOA) and interns 
are tracked by projected graduation date as they are a potential pool of candidates for employment.

New Employees: perspectives on Boeing

New employees have definite perspectives on Boeing and how it operates. Most new employees perceive that Managers are aware of their professional goals. Twice yearly meetings between the supervisor and the new employees are used for setting and evaluating goals. Sometimes project goals/timelines are unrealistic and must be adjusted. Twice yearly meetings are a minimum and may not be enough. All new employees expressed the desire to receive more feedback on job performance. Success/satisfaction seemed to be measured through performance reviews which isn't enough feedback. Lack of feedback requires new employees to develop a sense of personal satisfaction for a job well done without receiving any recognition or praise. New Employees are generally pleased with their career path but to be fully satisfied, their job must be challenging. Programs such as Learning Together, REACH, ONE, and Mentorships are available for the new employees; however, people are often unaware of these opportunities.

New employees perceive the following skills are important in their jobs:

- Technical Skills

- Strong Technical Skills

- Analysis Skills

- $\quad$ Soft Skills

- Creative Mindset

- Strong Work Ethic

- Clear Communication Skills

- Critical Thinking

- Team work

- Patience

\section{Career Development}

Managers have a desire to see Boeing keep the pipeline of engineers full. Boeing should do strategic hiring to relieve the gaps in experience and to hire continuously to ensure these gaps do not occur again, even in times of economic recession. Mentoring in many groups is not a formal process which implies that career planning with a mentor could be improved. A high attrition among engineers with less than 5 years of service to Boeing has been noted. "Didn't utilize me well" was one of the comments received by new employees that have left. All managers agree that communication is the key to knowing what a new employee is thinking. The new employee has a Development Plan that is assessed. Assessment is based on success and work ethic.

At some point every new employee must decide whether to go on a technical or managerial track. Managers suggest individuals learn about Boeing for at least three years before making this decision. Sometime during these three years the manager should ask the individual's desires and work with them to develop their plan. Normally the final decision is made around the 10-15 year point in a career. 
New Employees: Suggestions for Engineering Preparation

Interviews with new employees indicate that they decided to become an engineer in high school or college. This needs to occur earlier in the education pipeline. New employees gave some suggestions for changes in K-12 and undergraduate experiences.

For K-12

- More diversified classes to include engineering/majors to take in college

- Time management - balance life demands

- Good math and science foundation

For the University

- More project based learning

- Require co-op or internship

- Research emphasis

- Analysis skills

In summary, the STEM pipeline is not full for a variety of reasons. Boeing is engaged in many ways with the pipeline.

\section{Grand Solution and Opportunities}

Boeing is well positioned to take a lead role in developing the engineering pipeline to cultivate a world-class talent pool of engineering graduates. This process can and must begin in K-12 programs.

The Case for Boeing as a Leader

Nationally and globally, there are many K-12 programs and participants. NASA, Lockheed Martin, Intel, and Microsoft are some of the major players in K-12 efforts. However these efforts are disjointed. There is some collaboration, but more often each participant is developing its own approach. This is not efficient. There is tremendous amount of information on programs that have been developed to impact the K-12 pipeline, but not as much has been done to measure the effectiveness of these programs. As a result, very few best practices have been identified.

The K-12 STEM pipeline is critical not just for Boeing. It has an impact on the broader engineering community and is vital to U.S. prosperity and security. Boeing has this vision and should be commended. The U.S. in turn is a vital $\operatorname{cog}$ in the global economy.

It is encouraging that this global perspective is recognized by leaders within Boeing. As Mike Richey points out, "As a Large Scale Systems Integrator, we at Boeing have developed such feedback models in a collaborative group process to cooperatively design strategic business policies, to improve internal organizations and to create synergies of action among autonomous enterprises. We offer, to U. S. industry, academia and government, our expertise in facilitating a similar cross-sector collaboration to address the Gathering Storm problem." 
Boeing invests a significant amount of money in education, as is seen in Figure 4. The figure below shows a pie chart that indicates the money that Boeing spends on various education items such as student tuition reimbursement for Boeing employees in the Learning Together program, and the Boeing Leadership Center.

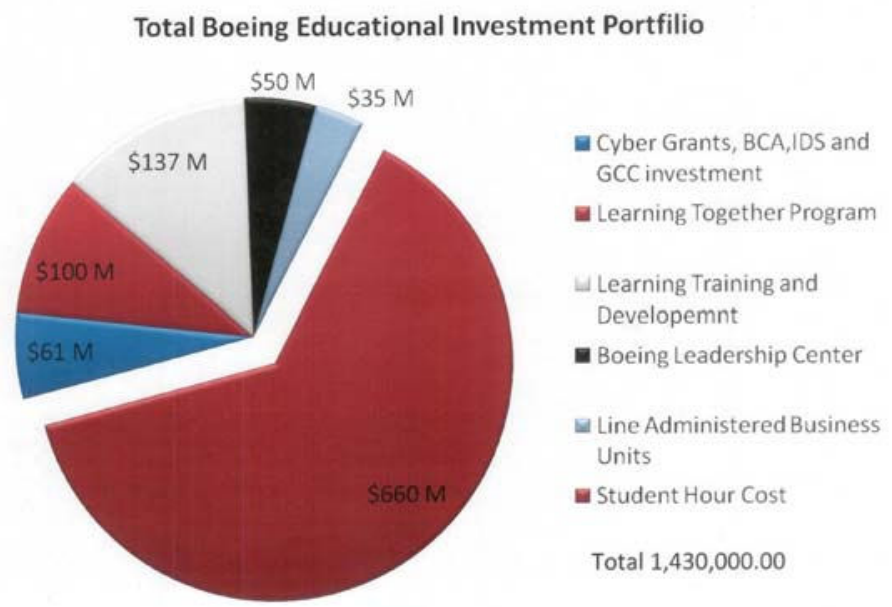

Figure 4 Boeing's investment in Education ${ }^{7}$

Boeing spends a total of 1.4 billion dollars for education. This is a significant sum of money. It shows Boeing's commitment to education. Most of this expenditure though is not directed toward the K-12 STEM pipeline.

A need exists for a system that defines, creates, and disseminates best practices for K-12 STEM education. Boeing as a leader in systems integration possesses the knowhow for integrating such a system. Commitment to the K-12 STEM pipeline exists within Boeing and should be developed further.

\section{Will K-12 STEM education work?}

There are several examples of such systems in place, but on a smaller scale than what is being advocated in this paper. Two cases in point; the FIRST ${ }^{8}$ robotics program and NASA's RAP (Robotics Alliance Project) ${ }^{9}$. Both are very well known programs. The FIRST robotics program is strongly supported by a consortium that includes Boeing. It has been a tremendous success. A study from Brandeis University has produced quantitative metrics that show the ability of the FIRST program to enthuse budding young engineers. Kids that participate in the FIRST program are ${ }^{8}$ :

1. Three times $(3 \mathrm{X})$ as likely to major in engineering,

2. Twice $(2 \mathrm{X})$ as likely to pursue a career in science and technology,

3. Four times $(4 \mathrm{X})$ as likely to pursue a career in engineering,

4. Twice $(2 \mathrm{X})$ as likely to volunteer in their community.

The Robotics Alliance Project is another great initiative from NASA. This project acts as the clearinghouse for all Robotics related information. The NASA vision for this project is to 
promote robotics in order to ensure success of robotic space missions. In a sense, NASA is the systems integrator for this project to promote robotics.

These are two examples of systems in place, on a small scale, that have enjoyed success measured by quantitative metrics. This gives further confidence that a consortium led by Boeing is a very viable initiative to promote $\mathrm{K}-12$ activities.

\section{Final Recommendations}

\section{The Near Term Goals}

The recommendations for Boeing (and industry) for the near term are:

1. The Welliver Fellowship is a wonderful program for university faculty. Fellows who have experienced this program can provide great testimonials. This program can easily be extended to K-12 STEM teachers, to let them experience Boeing. Clearly, there is a funding issue here, but for the immediate future it is suggested that 1 or 2 STEM K-12 teachers be initiated into the Welliver program as a trial experience. They could possibly be paired with a university Welliver faculty fellow. By this, the university Welliver fellow could participate in the professional development of the K-12 Welliver fellow.

2. Boeing has strategic research partnerships in place with eight universities in specific technology domains. The protocol for these partnerships is in place. This enables Boeing to tackle research problems in a relatively quick manner. The authors advocate strategic education partnerships with universities. These partnerships would be directed toward engaging the education community to develop strategies to address deficiencies in the STEM pipeline.

3. Boeing should work toward promoting engineering and the Boeing name earlier in the pipeline. The authors have several suggestions in this regard.

a. Boeing should sponsor an Industry-Academia Summit which will help define the role that Boeing can play in $\mathrm{K}-12$.

b. Teaching modules, based on Boeing case studies, can be developed for teachers.

c. Boeing is perceived as a leader in Lean and 10x methodologies. It has developed several training modules in this area. Some of these could be easily designed as modules for use in schools.

d. A web portal could be devised as a clearinghouse for disseminating the best practices in STEM education.

e. Boeing should develop a Signature Design or Science talent competition. This would help define the Boeing brand at an early stage in a budding young engineer or scientist.

f. There are several Boeing engineers who serve as mentors for college students as well as secondary school kids. More can be done. But more importantly, this needs to be recognized by the company in a meaningful way.

g. Boeing can get behind innovative programs such as the NSF Robert Noyce Teachers Scholarship Program. This program provides scholarships to college students but in return asks for a commitment to teaching in secondary schools.

h. Boeing is already supporting design competitions run by professional societies and it needs to continue its involvement. 
4. Teachers in elementary and secondary schools hold the key to success in filling the pipeline. To attract talented STEM individuals to education, it is vitally important that the compensation be attractive. Teachers' salaries in a majority of schools are inadequate. As a big corporation with a lot of clout, Boeing has the ability to lobby for higher K-12 teacher salaries, and it should.

\section{The Long Term Goals}

1. Boeing should become the focal point for K-12 pipeline information and models. The analogy for this is NASA's Robotics Alliance Project. The mission of this Project is "To create a human, technical, and programmatic resource of robotics capabilities to enable the implementation of future robotic space exploration missions." To achieve this mission, this project acts as the clearinghouse for all things robotic. Boeing's mission should be to "Create the complete resource for enabling STEM education in K-12."

2. K-12 education is a vast system and it can be potentially modeled, like other large systems, in some very sophisticated ways to predict its behavior and dynamics. Boeing as a leader in large scale systems integration, is unique positioned to be the leader in the modeling of the dynamics of the K-12 education pipeline. One could advocate the formation of a 'Center for Education Modeling', that can develop systems level models that will allow strategic decision making possible in identifying programs that give the greatest return.

3. It is also advocated to form a 'Center for Engineering Education Development' which will develop innovative programs in engineering education for Colleges, secondary, and primary schools. Both these Centers could reside at Boeing. These think tanks could be populated with Technical Fellows whose expertise is in engineering education.

4. A full-fledged Boeing K-12 teacher fellowship program can be developed, modeled after the strengths of the Welliver Fellowship. This program could be tailored in a way that is best for K-12 STEM education, rather than follow directly the model of the Welliver fellowship.

5. The Boeing University Relations Board should be morphed into the Education Relations Board. This new Board will oversee both University Relations and K-12 STEM relations.

\section{Financial Recommendation}

It is also recommended that Boeing, in a Phase 1 pilot study, should increase investment in K-12 programs by $50 \%$ of its current spending for K-12. This would enable Boeing to implement some of the short-term recommendations and begin considering the implementation of the long term goals. It is believed the financial commitment is extremely important for two reasons. First, it shows a Boeing commitment to K-12 education. Second, it will allow Boeing to begin the journey toward becoming the leader in the consortium for the K-12 education pipeline. 


\section{Conclusion}

The Engineering and Aerospace community needs a resurgence and reawakening in the way it thinks about engineering education and the STEM K-12 education system. It is imperative that emphasis on STEM start very early in the education pipeline; College is too late!

\section{Bibliography}

1, “Welliver Faculty Fellowship Program", accessed on December 14, 2009

http://www.boeing.com/educationrelations/facultyfellowship/index.html

Accessed on December 6, 2009.

2, NAE Engineer of 2020, http://www.nae.edu/cms/10372.aspx, accessed on March 16, 2010.

3. "Boeing attributes of an engineer", accessed on December 14, 2009

http://www.boeing.com/educationrelations/attributes.html

4. http://www.lockheedmartin.com/news/press_releases/2008/0122hq_lead-the-way.html, accessed on March 16, 2010 .

5. Sturtevant, D. J., 2008, “America Disrupted: Dynamics of the Technical Capability Crisis,” Engineering Systems Divisions, Massachusetts Institute of Technology.

6. Richey, M., Newton, P., and Stephens, R., Backus, G., and McPherson, B., "The S\&T Eco-System: Pressures From Kindergarten to Globalization," AC 2008-1063.

7. Boeing Corporate Philanthropy Report 2008

8. http://www.usfirst.org/ accessed on March 16, 2010.

9. http://robotics.nasa.gov/, accessed on March 16, 2010. 